\title{
KARAMAN İLİ KÜRESEL GÜNEŞ RADYASYONUNUN HELIOSAT METOT KULLANILARAK BELIRLENMESI
}

\author{
Selmin ENER RUŞEN (ORCID: 0000-0003-3389-5739)* \\ Enerji Sistemleri Mühendisliği Bölümü, Mühendislik Fakültesi, Karamanoğlu Mehmetbey Üniversitesi, Karaman, Türkiye \\ Akademik Enerji Araşttrma Grubu (AKEN), Mühendislik Fakültesi, Karamanoğlu Mehmetbey Üniversitesi, Karaman, Türkiye \\ Geliş/ Received: 18.03.2017 \\ Düzeltmelerin geliși / Received in revised form: 22.05 .2017 \\ Kabul / Accepted: 22.05.2017
}

\begin{abstract}
ÖZ
Çevresel ve ekonomik gereksinimler güneşi özellikle enerji talebinin giderek arttığı bu dönemde daha fazla kullanmamız gerektiğini göstermektedir. Kurulacak güneş enerji sistemlerin planlanması, maliyet analizi ve verimlilik değerlendirmeleri açısından yeryüzüne gelen güneş radyasyonunun doğru bir şekilde belirlenebilmesi önemlidir. Türkiye'de yüksek güneş enerjisi potansiyeline sahip olan Karaman İli güneş enerjisinden elektrik enerjisi üretmek için Enerji İhtisas Endüstri Bölgesi (EIEB) olarak belirlenmiştir. Bu bölgede kurulacak sistemlerin planlanmasında güneş enerjisi radyasyon girdisi çok dikkatli belirlenmelidir. Özellikle uzaktan algılama yöntemleri kullanılarak yapılan güneş radyasyonu tahmin modelleri geniş alanları kapsadığı ve kolay işlenebilir olduğu için oldukça avantajlıdır. Bu çalışmada uydu görüntüleri ile güneş radyasyonunu tahmin eden modellerden biri olan HELIOSAT metot tanıtılmıştır. Ayrıca 3 yıllık çalışma periyodunda Karaman İlinin güneş enerjisi potansiyeli ve iklimsel etkisi tespit edilmiştir. Elde edilen sonuçlar yeryüzünde ölçülen güneş ışınım şiddeti ile Bağıl MBE (Relative Mean Bias Error) ve Bağll RMSE (Relative Root Mean Square Error) istatistiksel testleri kullanılarak karşılaştııılmıştır.
\end{abstract}

Anahtar Kelimeler: Küresel güneş radyasyonu, uydu, HELIOSAT, uzaktan algılama, Karaman

\section{DETERMINATION OF THE GLOBAL SOLAR RADIATION POTENTIAL USING HELIOSAT METHOD FOR KARAMAN}

\begin{abstract}
Environmental and economic requirements have clearly demonstrated that we must use the sun as an eternal resource especially in this period that energy demand has increased gradually. For these investments, it is extremely important to determine some factors such as planning the systems, cost analysis, productivity evaluations. Solar energy inputs have carefully been determined in region where the systems will be installed and have been designated in Karaman as an Energy Specialized Industrial Zone (ESIZ). Estimation model from remote sensing methods has the edge over its advantages as it includes the very large area and being easily processable. In this work, HELIOSAT Method has been presented as a model that it estimates solar radiation with satellite images. Solar energy potential and climate effects of Karaman have been fixated in three-year study. Obtained results have been compared with radiation violence by using Relative MBE (Relative Mean Bias Error) and Relative RMSE (Relative Root Mean Square Error) statistical tests.
\end{abstract}

Keywords: Global solar radiation, satellite, HELIOSAT, remote sensing, Karaman

"Corresponding author / Sorumlu yazar. Tel.: +90 338226 2200; e-mail / e-posta: selmin.enerrusen@gmail.com 


\section{S. ENER RUŞEN}

\section{GİRIŞ}

Gelişmişlik düzeyinin bir göstergesi olarak enerji talebinin gün geçtikçe artması ve bununla birlikte fosil yakıtların giderek azalması yenilenebilir enerji kaynaklarının önemini arttırmaktadır. Güneş, rüzgâr, biokütle ve jeotermal gibi bilinen tüm yenilenebilir enerji kaynakları arasında en büyük enerji potansiyeline sahip, doğrudan veya dolaylı tüm enerji kaynaklarının ana kaynağı güneştir. Yeryüzüne bir yılda düşen güneş enerjisinin, yeryüzündeki tüm fosil yakıtların sağlayacağı enerjiden çok fazla olduğu bilgisi de pek çok araştırmacı tarafından vurgulanmıştır $[1,2]$. Bu denli büyük bir enerji kaynağından yüksek verimle faydalanabilmek için güneş radyasyonunun doğru ölçümü veya doğru tahmin edilebilmesi en öncelikli belirlenecek parametredir. Bu parametre; enerji sistemlerinin planlanması, maliyet hesaplamaları, verimlilik analizleri ve iklim değişiminin izlenebilmesi gibi işlemlerin gerçekleştirilebilmesi için yaygın olarak kullanılmaktadır.

İhtiyaç duyulan güneş radyasyonu bilgisine, direkt olarak ölçüm cihazları kullanan meteorolojik yer gözlem istasyonlarından veya geliştirilen matematiksel tahmin modelleri ile yaklaşık olarak ulaşılmaktadır. En güvenilir ve kesin küresel güneş radyasyonu direkt yer gözlemleri ile yapılan ölçümlerden elde edilmektedir. Ancak bu istasyonlar tüm dünya üzerinde yeterince yaygın değildir. Ayrıca yer gözlem istasyonlarının ilk kurulum maliyetlerinin yüksek olması, ölçüm aletlerinin rutin bakım ve onarımı gibi dezavantajları da bulunmaktadır.

Güneş radyasyonunun elde edilmesi için kullanılan diğer yöntem ise geliştirilen modeller yardımı ile tahmin edilmesi şeklindedir. Bu tahmin modelleri kullandıkları yöntemlere göre çeşitlilik göstermektedir. Yeryüzü gözlemleri kullanılarak oluşturulan matematiksel tahmin modellerinin yanı sıra özellikle son yıllarda uzaktan algılama teknolojisinin gelişmesiyle birlikte oldukça yaygın olarak kullanılan uydu tabanlı tahmin modelleri de bulunmaktadır[3-5]. Uydular geniş alanları yüksek zamansal ve mekânsal çözünürlükle görüntüleyerek yer istasyonlarının kurulamadığı bölgelerin de güneş enerjisi hesaplamalarının yapılmasını sağlayabilmektedir. Ayrıca uydular; kullanım, depolama, işleme ve erişim kolaylığı gibi diğer avantajlara da sahiptir. Uydu görüntüleri kullanarak güneş radyasyonu tahmini ilk kez 1986 yılında Cano ve arkadaşları [6] tarafindan yapılmıştır. HELIOSAT metot olarak adlandırılan bu model bulut ve açık gökyüzü indeksi şeklinde isimlendirilen temelde iki parametreyi hesaplayarak güneş radyasyonunu tahmin etmektedir.

Türkiye güneş enerjisi potansiyeli yüksek olan ülkeler arasındadır. Yaklaşık olarak günlük güneşlenme süresinin toplam 7,2 saat olduğu ve günlük toplam güneş radyasyonu değerinin ise $3,6 \mathrm{kWh} / \mathrm{m}^{2}$ olduğu tespit edilmiştir. Y1llık olarak yapılan hesaplamalarda ise toplam güneşlenme süresi 2640 saat ve ortalama toplam güneş radyasyonu şiddeti $1311 \mathrm{kWh} / \mathrm{m}^{2}$-yıl olarak belirlenmiştir. Bu değerlerin Avrupa ülkeleri ile karşılaştırıldığında çoğu ülkeden oldukça yüksek olduğu gözlenmektedir [7]. Elektrik İşleri Etüt İdaresi’nden alınan verilere göre yıllık toplam güneş enerjisi potansiyelinin en yüksek olduğu coğrafi bölgemiz $1460 \mathrm{kWh} / \mathrm{m}^{2}$ y1l ve 2993 saat/yıl değerleri ile Güney Doğu Anadolu bölgemizdir. İç Anadolu bölgemiz ise 1314 kWh/m²-y1l ve 2628 saat/yıl değerleri ile üçüncü sırada yer almaktadır [8]. Ayrıca iklim ve coğrafi özelliklerinin avantajları nedeniyle Konya ve Karaman bölgesi güneş enerjisi sistemlerinin en verimli işleyeceği bölgeler olarak görülmektedir ve Karaman İli Enerji İhtisas Bölgesi olarak belirlenmiştir [9, 10].

$\mathrm{Bu}$ çalışmada uydudan alınan görüntüler ile HELIOSAT metot kullanılarak güneş enerji potansiyeli yüksek olan Karaman İli için günlük güneş radyasyonu tahmini yapılmaktadır. Tahmin modelinden elde edilen günlük güneş radyasyonu değerlerinin doğruluğu geçmiş 3 yıllık gerçek yeryüzü güneş radyasyonu verileri ile karşılaştırılarak modelin hata oranı tespit edilmektedir. Ayrıca elde edilen sonuçlar kullanılarak bölgedeki iklimsel etkiler araştırılmıştır.

\section{MATERYAL VE METOT}

Güneş radyasyonu veri setleri pek çok alanda en önemli parametre olarak karşımıza çıkmaktadır. Bu alanlar arasında iklim değişikliği, yerleşim merkezleri mimari tasarımları, zirai verimlilik tahmini ve güneş enerjisi sistemlerinin planlanması gibi alanlar sıralanabilir. Günümüzde avantajları sebebiyle uydu görüntülerinin kullanıldığı güneş radyasyonu tahmin modelleri pek çok araştırmacı tarafından tercih edilmektedir [11-13]. Uydu tabanlı güneş radyasyonu tahmin modelleri ve kullanılan uydu görüntülerinin detayları aşağıda anlatılmaktadır.

Meteorolojik Uydular: Geniş alanlarda hızlı ve çözünürlüğü iyi görüntüler sağlaması nedeniyle meteorolojik uydu görüntüleri pek çok alanda olduğu gibi güneş radyasyonunun tahmininde de yaygın olarak kullanılmaktadır. Bu uydular sabit yörüngeli ve kutupsal yörüngeli uydular olmak üzere ikiye ayrılmaktadır. Dünyadan yaklaşık olarak 36000 km kadar yükseklikte olup dünyanın ekvator düzlemi üzerinde bir yörünge üzerinde ve dünya ile aynı açısal hızla dönen uydular sabit yörüngeli olarak adlandırılmaktadır. Gün içinde farklı zaman aralıklarında ve sürekli aynı bölgeyi (en fazla 15 dakika) yaklaşık $1 \mathrm{~km}$ çözünürlük ile gözlemleme özelliklerine sahiptir [14-16]. Sürekli olarak dünyayı gözleyen beş büyük sabit yörüngeli meteorolojik uydu bulunmaktadir. Bunlar Avrupa EUMETSAT'a ait METEOSAT $\left(0^{\circ}\right)$. ABD'ye ait GOES-E $\left(75^{\circ}\right)$ ve GOES-W 
$\left(135^{\circ}\right)$. Japonya'ya ait GMS $\left(140^{\circ}\right)$ ve Hindistan'In INSAT $\left(93^{\circ}\right)$ şeklindedir [17-9]. Şekil 1 bu sabit yörüngeli uyduları ve kapsama alanlarını dünya haritası üzerinde göstermektedir.

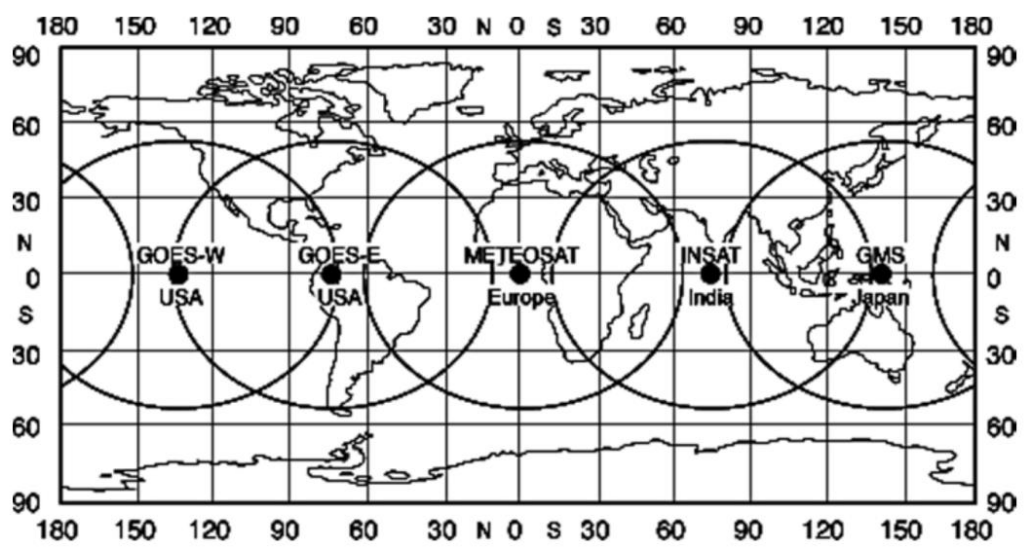

Şekil 1. Sabit yörüngeli meteorolojik uydular ve kapsama alanları [17]

1977 yılından bu güne Avrupa Meteoroloji Uyduları İşletme Teşkilatı (EUMETSAT) meteorolojik uydular serisi METEOSAT ile gözlemler yapmaktadır. İlk firlatılan uydular olan METEOSAT First Generation (MFG) toplam 7 tane uydu serisinden oluşmuştur ve 2005 yılına kadar 3 ana kanaldan görüntüler sağlamıştır. Bunlar görünür bölge kanalı (visible channel) $0.5-1.1 \mu \mathrm{m}$ kızıl ötesi kanal (termal infrared channel) $10,5-12,5 \mu \mathrm{m}$ ve su buharı kanalı (water vapour channel) 5,7-7,1 $\mu \mathrm{m}$ şeklindedir. 2005 yılından sonra ise 2020 yılına kadar çalışması planlanmış olan ikinci nesil meteorolojik uydular METEOSAT Second Generation (MSG) kullanılmaktadır. Daha fazla spektral kanal ile (toplam 12 tane) ve daha üstün özellikler ile 15 dakikada bir. 1 km'ye kadar hassasiyet ile görüntü alabilmektedirler [18-19].

Uydu ile Modelleme: Güneş radyasyonunu tahmin modellemelerinde üç temel yaklaşım öne çıkmaktadır. Bunlar uydu görüntüleri ile işlem yapan istatistiksel model, fiziksel ve hibrit modellerdir [10, 19]. Bu çalş̧mada güneş radyasyonu tahmini için uydu tabanlı modeller arasında en yaygın olan HELIOSAT Metot kullanılmıştır.

HELIOSAT Metot: Cano vd.leri [6] tarafından 1986 yılında oluşturulan bu model 1996 yılında bulut indeksi ve açık gökyüzü radyasyonu parametreleri eklenerek Beyer ve ark, [20] tarafindan yeniden geliştirilmiştir. Bu modelde yeryüzüne ulaşan açık gökyüzü güneş radyasyonu ve meteorolojik uydu görüntüleri işlenerek bulut indeksi hesaplanmaktadır. Hesaplanan değerlerden yeryüzüne ulaşan küresel güneş radyasyonu tahmini yapılmaktadır. Öncelikle uydu görüntülerinin piksel sayımı yapılarak relative albedo $\rho$ elde edilmektedir. Albedo yardımı ile bulut indeksi $n$ hesaplanmaktadır. Bahsedilen relative albedo $\rho$ değeri Denklem (1)'de tanımlanmaktadır [20]:

$$
\rho=\frac{C-C_{0}}{0.7 f \cos \theta_{z}\left(\cos \theta_{z}\right)^{0.15}}
$$

Burada $C$ : uydu görüntüsü piksel sayım değeri. $C_{o}$ : offset değeri. $\theta_{z}:$ zenith açısı. $f$ : Güneş-dünya arası düzeltme faktörü olarak tanımlanmaktadır. Bulut indeksi $n$ ise her bir uydu görüntüsü için:

$$
n=\frac{\rho-\rho_{\min }}{\rho_{\max }-\rho_{\min }}
$$

eşitliğinden hesaplanmaktadır. Denklem (2)'de $\rho_{\max }$ ve $\rho_{\min }$ bulutlu (kapalı) ve açı gökyüzü koşullarındaki relative albedo değerleridir $[19,21]$. Maksimum (max) ve minimum (min) piksel değerleri görünür bölge spektral kanalından alınan uydu görüntülerinden bulunmaktadır. Hesaplanan bulut indeksi yoğunlukla 0-1değer aralığında değişmektedir.

Yeryüzündeki gerçek güneş radyasyonunu, hesaplanan açık gökyüzü radyasyonuna bölünerek normalize edilir. Bu denklem ise açık gökyüzü indeksi $k^{*}$ olarak isimlendirilmektedir.

$$
k^{*}=\frac{G}{G_{\text {clear }}}
$$

Denklem (3)'de $G_{\text {clear }}$ açık gökyüzü koşullarındaki güneş radyasyonunun saatlik değerini göstermektedir ve Denklem (4) ile verilmiştir [20] : 


\section{S. ENER RUŞEN}

$$
G_{\text {clear }}=G_{d n ; \text { clear }} \cos \theta_{z}+G_{\text {dif;clear }}
$$

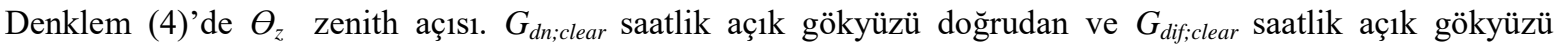
saçılmış radyasyon değerlerini göstermektedir. Linke bulanıklık faktörü $T_{L}$ dikkate alınarak bu değerlerin hesaplamaları yapılmaktadır. Detaylı bilgiye birçok araştırmacının yapmış olduğu çalışmalardan ulaşılabilir [2226]. Saatlik olarak yapılan hesaplamalardan günlük açık gökyüzü radyasyonu değerlerine basitçe toplama ile geçilmektedir. Buradan Denklem (4) ve (5) saatlik yeryüzü güneş radyasyonu $G_{g}$ 'nin elde edilmesinde kullanılmaktadır [21].

$$
G_{g}=k^{*} G_{\text {clear }}
$$

Burada $k^{*}$ ve $n$ arasında bulunan ilişki incelendiğinde basitçe Denklem (6)'daki gibi bir bağıntı elde edilmektedir. Hammer [21] tarafından 2000 yılında yapılmış olan bu çalışma aşağıdaki şekilde verilmiştir.

$$
k^{*}=\left\{\begin{array}{cc}
1,2 & n<-0,2 \\
1-n & n \in[-0,2.0,8] \\
2,0667-3,6667 n+1,6667 n^{2} & n \in[0,8 \cdot 1,1] \\
0,05 & n>1,1
\end{array}\right.
$$

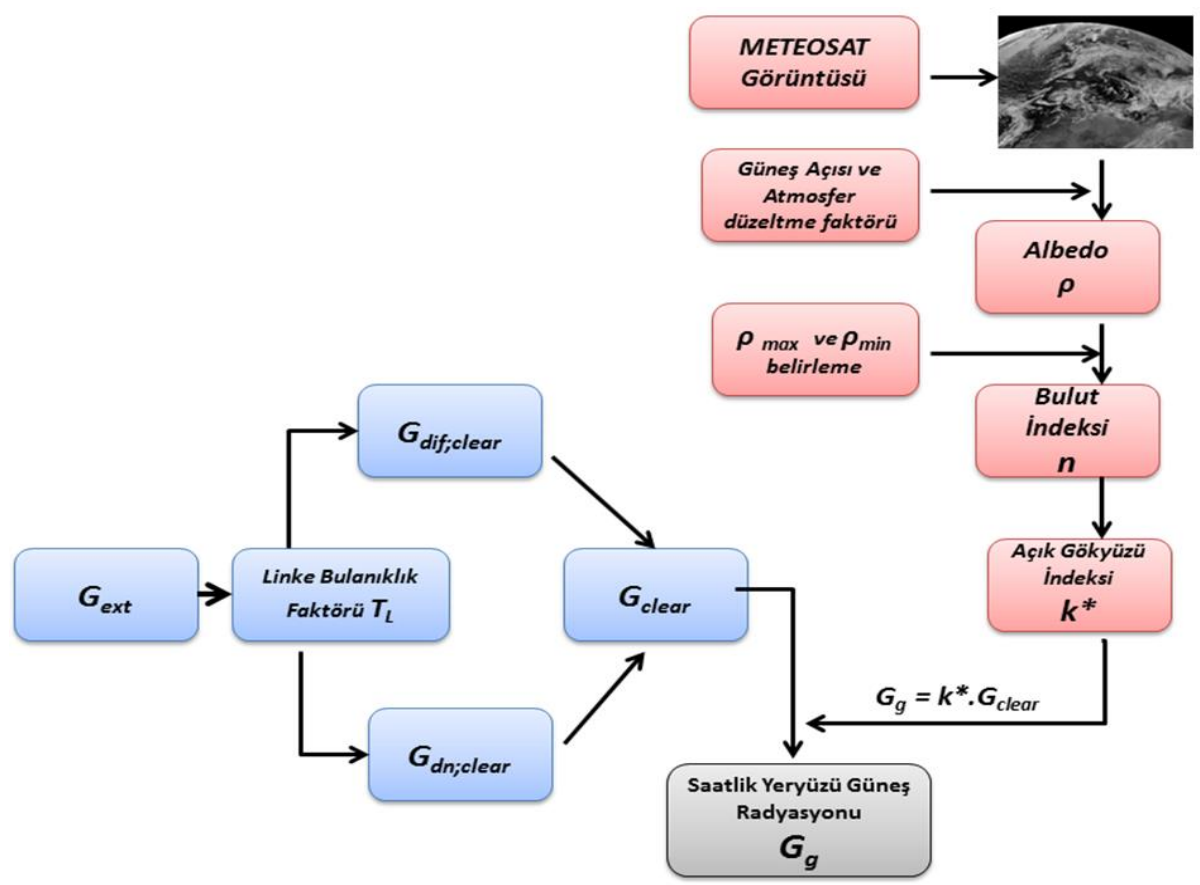

Şekil 2. HELIOSAT Metot hesaplama aşamalarını gösteren akış diyagramı [27]

HELIOSAT Metot ile ilgili yapılan tüm hesaplama aşamaları ve açıklamalar Şekil 2'de şematik olarak verilmektedir. Yukarıda detaylı olarak bahsedilen açık gökyüzü radyasyonunun hesaplanması için atmosfer dışı güneş radyasyonu $\left(G_{e x t}\right)$ ile uydu görüntülerinden elde edilen bulut indeksi ve Linke bulanıklık faktörü $T_{L}$ doğrudan ve yaygın güneş radyasyonunun hesaplama aşamasında kullanılmaktadır. Ayrıca şekilde görüldüğü gibi uydu görüntüsünün işlenmesi sonucu relative albedo ve bulut indeksi elde edilmesi işlemlerinden önce güneş konumu ve atmosferik faktörler dikkate alınarak görüntülerin düzeltmesi yapılmaktadır.

Veriler: İkinci nesil uydulardan olan METEOSAT-8 uydusundan alınan görüntüler ve HELIOSAT Metot kullanılarak Karaman ili için geçmiş 3 yıllık küresel günlük güneş radyasyonu tahmini yapılmıştır. Tahmin

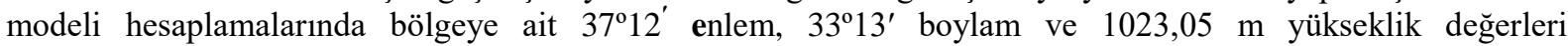
kullanılmıştır. Şekil 3'de Meteosat-8 uydusundan Karaman İli için görüntü alınmasının şematik gösterimi verilmektedir.

Bu çalışmada tahmin modeli ile belirlenen günlük güneş radyasyonu değerleri 3 yıllık süre periyodunda Devlet Meteoroloji İşleri Genel Müdürlüğü’nden (DMI) alınan bölgeye ait gerçek yeryüzü ölçümleri ile kıyaslanmıştır. 
Ayrıca bölgenin iklim tipi belirlenerek güneş radyasyonu değerleri ile iklimin ilişkisi araştırılmıştır. İklim bilgisi Köppen-Geiger iklim sınıflandırması ile belirlenmiştir. Karaman için iklim tipi BSk, soğuk step iklimi ya da soğuk yarı kurak iklim olarak tanımlanmaktadır [28].

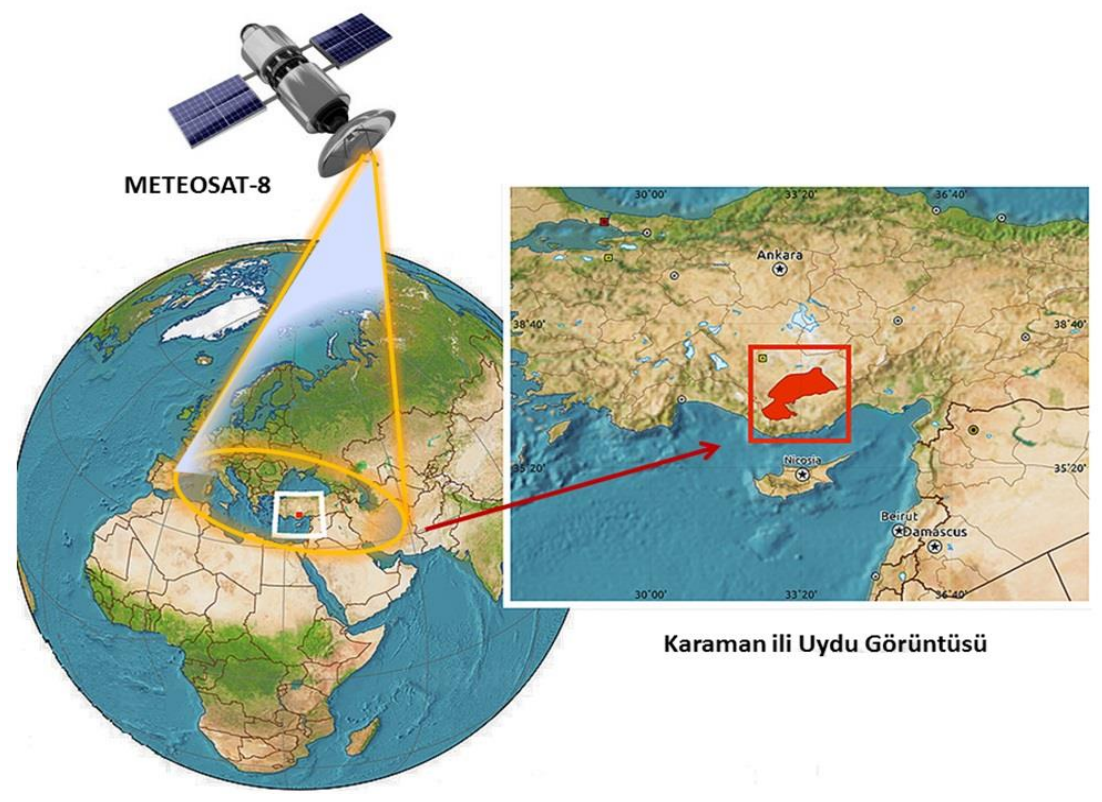

Şekil 3. Meteosat-8 uydusundan Karaman ili için görüntü alınmasının şematik gösterimi

Karşılaştırma Teknikleri: Bu çalışmada HELIOSAT Metot ile tahmin edilen günlük güneş radyasyonu değerleri, gerçek yeryüzü ölçümleri ile Bağıl MBE (Relative Mean Bias Error) ve Bağıl RMSE (Relative Root Mean Square Error) testleri kullanılarak karşılaştırılmıştır. Aşağıda günlük güneş radyasyonu arasındaki fark $\left(\omega_{e}\right)$ denklem (7)'de, Bağıl MBE ve Bağıl RMSE değerleri ise denklem (8) ve (9)'da verilen eşitliklerde tanımlanmaktadır.

$$
\begin{aligned}
& \omega_{e}=H_{i c}-H_{i m} \\
& r M B E=\left[\left(\sum_{1}^{d}\left(H_{i c}-H_{i m}\right)\right) / d\right] / H_{m} \\
& r R M S E=\left[\left\{\left(\sum_{1}^{d}\left(H_{i c}-H_{i m}\right)^{2}\right) / d\right\}^{1 / 2}\right] / H_{m}
\end{aligned}
$$

Denklem (8) ve (9)'da bulunan $d$ veri sayısını, $H_{i c}$ model ile tahmin edilen $i$. değeri, $H_{i m}$ ölçülen yer verisinin $i$. değerini ve $H_{m}$ ölçülen yer verisinin günlük ortalama değerini göstermektedir [33]. Bulunan Bağıl RMSE değeri HELIOSAT metot uygulanarak bulunan güneş radyasyonu tahmin değerlerinin doğruluğu hakkında bilgi vermektedir.

\section{BULGULAR VE TARTIŞMA}

Çalışma periyodu olarak son 3 yıllık zaman aralığı seçilmiştir ve Karaman ili için görünür bölgede alınmış METEOSAT-8 uydu görüntüleri ile HELIOSAT Metot kullanılarak aylık ortalama günlük küresel güneş radyasyonu şiddeti tahmin edilmiştir. Şekil 4'de tahmin edilen üç yıllık güneş radyasyonu şiddeti değerlerinin günlere göre dağılımı gösterilmektedir.

Ayrıca Tablo 1'de aylık ortalama günlük küresel güneş radyasyonu şiddeti değerleri seçilen çalışma periyodundaki her yıl için verilmektedir. Yıllık ortalama değerleri ise Tablo 1'in son satırında verilmektedir.

Her bir yıl için yer gözlem istasyonlarından alınan küresel güneş radyasyonu değerleri ile HELIOSAT Metot kullanılarak hesaplanan değerler kıyaslanarak Bağıl RMSE ve Bağıl MBE istatistiksel testleri yapılmıştır. 


\section{S. ENER RUŞEN}

Sırasıyla Bağıl RMSE ve Bağıl MBE değerleri Karaman için 1. yılda 0,21 ve -0,09 olarak hesaplanmıştır. 2. ve 3. yıllarına ait Bağıl RMSE değerleri aynı olup 0.36 olarak bulunmuştur. Bağıl MBE değerleri ise 2. yılı için 0,10 ve 3. yıl için -0,11 olarak tespit edilmiştir. Şekil 5'de bu değerler grafik ile gösterilmektedir.

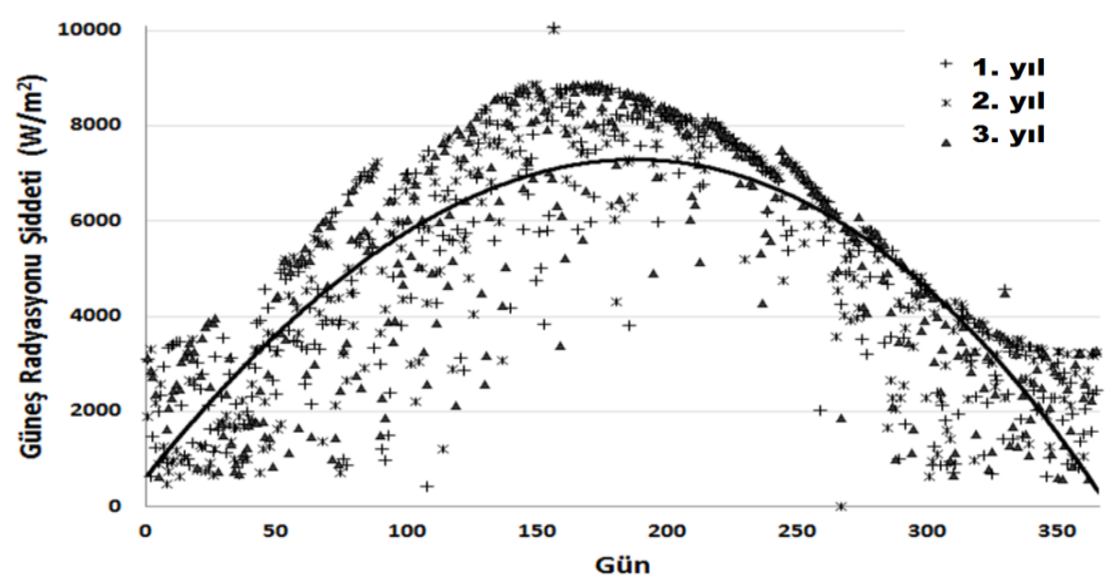

Şekil 4. HELIOSAT Metot ile tahmin edilen üç yıllık güneş radyasyonu şiddeti değerlerinin günlere göre dağılımı

Tablo 1. Karaman İli için HELIOSAT Metot kullanılarak geçmiş 3 yıl için tahmin edilen aylık ortalama günlük güneş radyasyonu şiddeti değerleri $\left(\mathrm{W} / \mathrm{m}^{2}\right)$

\begin{tabular}{|l|c|c|c|}
\hline \multicolumn{1}{|c|}{ Ay / Yıl } & $\mathbf{1}$ & $\mathbf{2}$ & $\mathbf{3}$ \\
\hline Ocak & 2156,34 & 1566,13 & 2514,27 \\
\hline Şubat & 3213,91 & 2700,61 & 2368,61 \\
\hline Mart & 4498,95 & 4674,83 & 4436,21 \\
\hline Nisan & 5243,84 & 5455,63 & 5173,62 \\
\hline Mayis & 6922,97 & 7268,26 & 7151,08 \\
\hline Haziran & 7704,25 & 8068,29 & 7786,45 \\
\hline Temmuz & 7893,99 & 7849,16 & 7903,79 \\
\hline Ağustos & 7415,34 & 7402,23 & 7098,11 \\
\hline Eylül & 5958,33 & 5646,85 & 6331,03 \\
\hline Ekim & 4090,27 & 3858,47 & 4266,43 \\
\hline Kasım & 2500,11 & 3197,83 & 2813,37 \\
\hline Aralık & 2164,81 & 2756,54 & 2159,93 \\
\hline Yıllık Ortalama & $\mathbf{4 9 8 0 , 2 6}$ & $\mathbf{5 0 3 7 , 0 7}$ & $\mathbf{5 0 0 0 , 2 4}$ \\
\hline
\end{tabular}

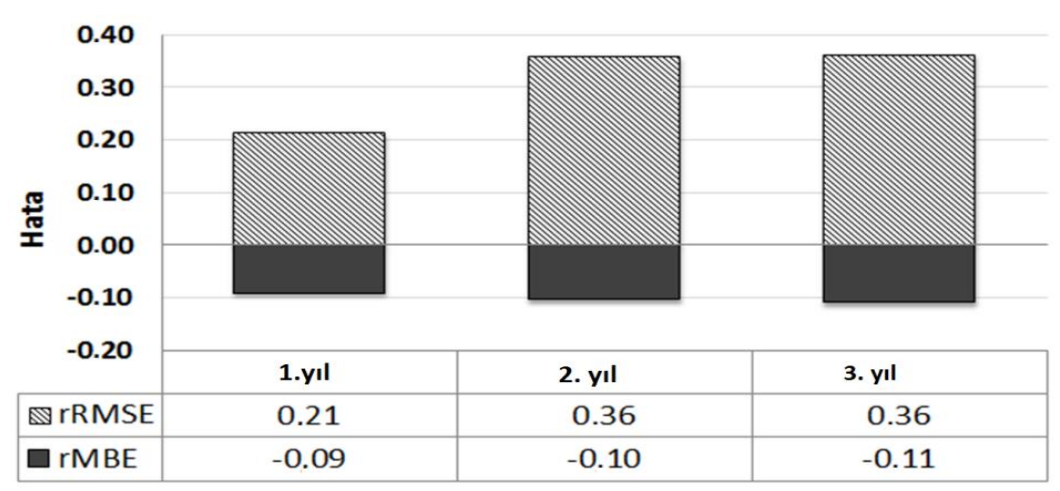

Şekil 5. HELIOSAT metot ile hesaplanan yıllık ortalama günlük güneş radyasyonunun yer verilerine göre Bağıl RMSE ve Bağıl MBE istatistiksel test değerleri 


\section{SONUÇLAR}

Güneşin bitmez enerji kaynağı ve dünyamızın geleceği açısından son derece önemli olduğu bilinen bir gerçektir. Bu nedenle elektrik elde etmede, binalarda, tarımsal alanda, enerji planlanmasında, enerji ve verimlilik analizlerinde, iklimsel araştırmalarda güneşten maksimum fayda sağlamak üzere çalışmalar yapılmaktadır. Bu çalışmaların en başında yapılması gereken ise güvenilir güneş radyasyonu bilgisinin elde edilebilmesidir. Güneş radyasyonunu elde etmek için yeryüzü güneş gözlem istasyonlarında doğrudan ölçümler en güvenilir yöntemdir. Fakat bu istasyonların yaygın olmaması, uzun süreli ve güvenilir verilerin alınamaması, ölçümleme ve maliyet gerektirmesi doğru verilerin alınmasını engellemektedir. Tüm bu zorluklar, küresel güneş radyasyonunun doğrudan ölçülmesi yerine gerçeğe yakın sonuçlar veren tahmin modellerinin geliştirmesine yol açmıştır. Dünyada yaygın olarak kullanılan bu tahmin modellerinden biri uydu tabanlı HELIOSAT Metot'tur. HELIOSAT Metot meteorolojik uydu görüntüleri kullanarak geniş alanlarda etkili tahminler yapmaya olanak sağlayan önemli ve yaygın kullanılan bir tahmin modelidir.

Bu çalışmada, HELIOSAT Metot detaylarıyla anlatılarak, Karaman İli için toplam 3 yıllık küresel güneş radyasyon şiddeti tahmin edilmiştir. Tahmin edilen aylık ortalama günlük güneş radyasyonu şiddeti değerleri Tablo 1'de verilmiştir. Ayrıca yıllara göre tahmin edilen ortalama günlük güneş radyasyonu şiddeti değerlerinin grafiği ise Şekil 4'Te gösterilmektedir. Seçilen yıllara ait tahmin değerlerinden iklim etkisi incelendiğinde, yaz aylarında güneş radyasyonunun yükselme yönünde, kış ve bahar aylarında ise yaygın bir dağılım gösterdiği gözlenmektedir. Tüm yıllar geneline bakıldığında ise günlere göre dağılımında yaklaşık aynı değerlerin elde edildiği görülmektedir.

HELIOSAT Metot ile yapılan tahminin gerçek sonuçlarla ne kadar örtüştüğünü belirlemek amacıyla seçilen 3 yıl için Karaman yeryüzü verileri kullanılarak istatistiksel testler yapılmıştır. Bilindiği gibi, tahmin edilen değerler gerçek değerlere ne kadar yakınsa Bağıl RMSE değeri o kadar küçük olmaktadır. Buradan, tahmin edilen değerlerin seçilen 3 yıl için gerçek değerlere çok yakın olduğu elde edilen ortalama Bağıl RMSE $(0,31)$ değerlerinden görülmektedir. Ayrıca Bağıl MBE hata analizi, karşılaştırılan verilerin uzun dönem performansları hakkında bilgi vermektedir. 3 yıllık süreçte Bağıl MBE ortalama -0,10 değerinde olup iyi tahmin performansı sonuçlarına uygun olarak küçük bir değerdedir. Yapılan araştırma sonuçlarına göre, Karaman ili için uydu görüntüleri ile tahmin yapan HELIOSAT Metot ve yeryüzü ölçümlerinden alınan veriler yaklaşı olarak aynı güven aralığında bulunmaktadır. Coğrafik ve iklimsel özellikleri nedeniyle Karaman İli için HELIOSAT metot ile yapılan günlük küresel güneş radyasyonu tahminlerinin başarılı olduğu gözlenmektedir. Bu modelin güvenilirliği farklı iklim koşulları ve farklı istasyonlar için araştırılmalıdır.

\section{TEŞEKKÜR}

Çalışmada kullanılan uydu verilerinin temini ile hesaplamaların yapılması aşamasında verdiği destekten dolayı Oldenburg Üniversitesi ve Dr. Annette Hammer'a teşekkür ederim. Ayrıca karşılaştırmak amaçlı kullanılan yeryüzü verilerin temin edildiği Devlet Meteoroloji İşleri Genel Müdürlüğü’ne teşekkür ederim. Tüm akademik çalışmalarımda her zaman sonsuz destek olan Prof. Dr. Bülent Akınoğlu'na şükranlarımı sunarım.

\section{KAYNAKLAR}

[1] VARINCA, K.B., TALHA, M., “Türkiye'de Güneş Enerjisi Potansiyeli ve Bu Potansiyelin Kullanım Derecesi. Yöntemi ve Yaygınlığı Üzerine Bir Araştırma”, UGHEK 2006 I. Ulusal Güneş ve Hidrojen Enerjisi Kongresi, Eskişehir, Türkiye, 2006.

[2] ÖZDEMİR, Y., "Uydu Tabanlı Kuadratik Model ile Türkiye'de Güneş Radyasyonu Dağılımının Belirlenmesi”, Yüksek Lisans Tezi, Gazi Üniversitesi, Ankara, Türkiye, 2012.

[3] ANGSTRÖM, A., "Solar and Terrestrial Radiation", Quart. J. Roy. Met. Soc., 50, 121-126, 1924.

[4] YANG, K., HUANG, G.W., TAMAI, N., "A Hybrid Model for Estimating Global Solar Radiation”, Solar Energy, 70(1), 13-22, 2001.

[5] AKInOGLU, B.G., ECEVIT, A., "Construction of a Quadratic Model Using Modified Angström Coefficients to Estimate Global Solar-Radiation”, Solar Energy, 45, 85-92, 1990.

[6] CANO, D., MONGET, J., AlBUISSON, M., GUILlARD, H., REGAS, N., WALD, L., “A Method for the Determination of the Global Solar Radiation from Meteorological Satellite Data”, Solar Energy, 37, 31-39, 1986. 
[7] KIRBAŞ, İ., ÇİFÇİ, A., İŞYARLAR, B., "Burdur İli Güneşlenme Oranı ve Güneş Enerjisi Potansiyeli Sunbathing Rate and Solar Energy Potential of Burdur, Turkey", Mehmet Akif Ersoy Üniversitesi Fen Bilileri Enstitüsü Dergisi, 4(2), 20-23, 2013.

[8] http://www.eie.gov.tr (erişim tarihi 22.03.2015).

[9] KARACA, İ.H., GÜRKAN, E.C., YAPAR, H., "Konya ve Civarının Güneş Enerjisi Potansiyeli ve Selçuklu Belediyesi Muhtar Evlerinde Güneşten Elektrik Üretim Sistemi Uygulaması”, I Konya Kent Sempozyumu, 275-292, Konya, Türkiye, 2011.

[10] ENER RUSEN, S., "Uydu Görüntülerini Kullanarak Konya ve Karaman İlleri İçin Güneş Enerjisi Potansiyelinin Belirlenmesi”, 3. Anadolu Enerji Sempozyumu, Muğla, Türkiye, 2015.

[11] ENER RUSEN, S., HAMMER, A., AKINOGLU, B.G., "Estimation of Daily Global Solar Irradiation by Coupling the Ground Measurements of Bright Sunshine Hours to the Satellite Imagery", Energy, 58, 417425, 2013.

[12] DIABATE, L., MOUSSU, G., WALD, L., "Description of an Operational Tool for Determining Global Solar Radiation at Ground Using Geostationary Satellite Images”, Solar Energy, 42(3), 201-207, 1989.

[13] BAKIRCI, K.., "Correlations for Estimation of Daily Global Solar Radiation with Hours of Bright Sunshine in Turkey”, Energy, 34(4), 485-501, 2009.

[14] DAGESTAD, K.F., "Estimating Global Radiation at Ground Level from Satellite Images", PhD Thesis. University of Bergen, Bergen, 2005.

[15] ZELENKA, A., PEREZ, R., SEALS, R., RENNE, D., "Effective Accuracy of Satellite-Derived Hourly Irradiances", Theor. Appl. Climatology, 62, 199-207, 1999.

[16] JES'US, P., LUIS, Z.F., LOURDES, RAM'IREZ, M., Solar Radiation Derived from Satellite Images. In B. VIOREL (Eds.), Modelling Solar Radiation at the Earth's Surface, (pp. 449-462), Romania, Springer, 2008.

[17] HAUSCHILD, H., REISS, M., RUDULF, B., SCHNEIDER, U., "Die Verwendung von Satellitendaten im WZN", Met. Zeitschrift, 1, 58-56, 1992.

[18] http://www.eumetsat.int (erişim tarihi 01.04.2015).

[19] ENER RUSEN, S., "Linking Satellite Imagery to Bright Sunshine Hours for the Estimation of Global Solar Irradiaiton", PhD Thesis, Middle East Technical University, Ankara, Turkey, 2013.

[20] BEYER, H., COSTANZO, C., HEINEMANN, D., "Modifications of the HELIOSAT Procedure for Irradiance Estimates from Satellite Images”, Solar Energy, 56, 207-212, 1996.

[21] HAMMER, A., “Anwendungspezifische Solar Strahlungsinformationen Aus Meteosat-Daten”, PhD Thesis, Carl von Ossietzky University, Oldenburg, Germany, 2000.

[22] INEICHEN, P., "Conversion Function Between the Linke Turbidity and the Atmospheric Water Vapor and Aerosol Content”, Solar Energy, 82(11), 1095-1097, 2008.

[23] BASON, F., "Linke's Turbidity Factor Applied to Worldwide Global Horizontal Irradiance Measurements", Aarhus University and Denmarks Meteorological Institute, 2-7, 2007.

[24] KASTEN, F., "The Linke Turbidity Factor Based on Improved Values of the Integral Rayleigh Optical Thickness", Solar Energy, 56, 239-244, 1996.

[25] REMUND, J., “Aerosol Optical Depth and Linke Turbidity Climatology”, Description for Final Report of IEA SHC Meteotest, 36, 2009.

[26] KANDIRMAZ, H., "A Model for the Estimation of the Daily Global Sunshine Duration from Meteorological Geostationary Satellite Data". International Journal of Remote Sensing, 5061-5071, 2006.

[27] HAMMER, A., HEINEMANN, D., HOYER, C., KUHLEMANN, R., LORENZ, E., MULLER, R., BEYER, H.G., "Solar Energy Assessment Using Remote Sensing Technologies". Remote Sens. Environ, 86(3), 423-432, 2003.

[28] PEEL, M.C., FINLAYSON, B.L., MCMAHON, T.A., "Updated World Map of the Köppen-Geiger Climate Classification”, Hydrol. Earth Syst. Sci., 11, 1633-1644, 2007. 